\title{
Pteridaceae (Polypodiopsida) do Campo Experimental da Embrapa Amazônia Oriental, município de Moju, estado do Pará, Brasil ${ }^{1}$
}

\author{
Sebastião Maciel $^{2,3,4}$ e Marcio Roberto Pietrobom ${ }^{3}$
}

Recebido em 30/05/2008. Aceito em 26/11/2008

RESUMO - (Pteridaceae (Polypodiopsida) do Campo Experimental da Embrapa Amazônia Oriental, município de Moju, estado do Pará, Brasil). Neste trabalho apresenta-se o tratamento taxonômico da família Pteridaceae como parte do projeto "Licófitas e monilófitas dos ecossistemas paraenses", que vem sendo realizado com o objetivo de identificar e catalogar as espécies da flora estadual. O Campo Experimental da Embrapa Amazônia Oriental está localizado no município de Moju e abrange uma área total de 1059 hectares, composta por uma cobertura vegetal de floresta de terra firme predominante e outra de floresta de igapó. Para análise e identificação taxonômica dos exemplares coletados, foram utilizadas técnicas usuais e literatura especializada. São apresentadas chaves para identificação de gêneros e espécies, além de descrições, ilustrações, comentários, dados de distribuição e habitat. A família Pteridaceae está representada na área estudada por 14 espécies: Acrostichum aureum L., Adiantum cajennense Willd. ex Klotzsch, A. dolosum Kunze, A. glaucescens Klotzsch, A. multisorum A. Samp., A. paraense Hieron., A. tetraphyllum Humb. \& Bonpl. ex Willd., A. tomentosum Klotzsch, Ananthacorus angustifolius (Sw.) Underw. \& Maxon, Anetium citrifolium (L.) Splitg., Hecistopteris pumila (Spreng.) J. Sm., Pityrogramma calomelanos (L.) Link var. calomelanos, Polytaenium guayanense (Hieron.) Alston, Vittaria lineata (L.) Sm. Duas espécies (A. dolosum e A. multisorum) são novas referências para o estado do Pará.

Palavras-chave: Amazônia, flora, samambaias, taxonomia

ABSTRACT - (Pteridaceae (Polypodiopsida) of the Embrapa Amazônia Oriental Experimental Farm, Moju municipality, Pará state, Brazil). In this study the taxonomic treatment of the family Pteridaceae is presented as part of the project "Lycophytes and monilophytes of the ecosystems of Pará", which aims to identify and list the species of the local flora. The experimental farm of Embrapa Amazônia Oriental lies in Moju municipality and comprises 1059 hectares, primarily covered by non-flooded lowland rain forest and secondly by flooded lowland rainforest. Usual techniques and specialized literature were used for analyses and taxonomic identification of the collected specimens. Keys for the identification of genera and species are given, plus descriptions, illustrations, comments and distribution and habitat data. The family Pteridaceae is represented by 14 species in the study area: Acrostichum aureum L., Adiantum cajennense Willd. ex Klotzsch, A. glaucescens Klotzsch, A. paraense Hieron., A. tetraphyllum Humb. \& Bonpl. ex Willd., A. tomentosum Klotzsch, Ananthacorus angustifolius (Sw.) Underw. \& Maxon, Anetium citrifolium (L.) Splitg., Hecistopteris pumila (Spreng.) J. Sm., Pityrogramma calomelanos (L.) Link var. calomelanos, Polytaenium guayanense (Hieron.) Alston, Vittaria lineata (L.) Sm., Adiantum dolosum Kunze and A. multisorum A. Samp. The latter two are new records for Pará state.

Key words: Amazon, flora, ferns, taxonomy

\section{Introdução}

A família Pteridaceae é bastante controversa devido à falta de consenso acerca da circunscrição e posição hierárquica das subfamílias de Pteridaceae (Moran \& Yatskievych 1995; Prado et al. 2007). Por exemplo, Ching (1940) reconhece duas tribos Lonchitideae e Pterideae e na classificação de Copeland (1947) Pteridaceae não possui subdivisões e inclui gêneros das famílias Dicksoniaceae e Dennstaedtiaceae. Tryon \& Tryon (1982) reconhecem seis tribos Adianteae, Ceratopterideae, Cheilantheae, Platyzomateae, Pterideae e Taenitideae. No tratamento de Tryon et al. (1990) Pteridaceae foi dividida em seis subfamílias (Adiantoideae, Ceratopteridoideae, Cheilanthoideae, Platyzomatoideae, Pteridoideae e Taenitidoideae) algumas bem definidas e outras mais complexas. Segundo Tryon et al. (1990) e Prado et al. (2007), Vittariaceae possui gêneros como Vittaria Sm., Ananthacorus Underw. \& Maxon in Maxon e Hecistopteris J. Sm., fortemente relacionados a Adiantum L. (Pteridaceae).

Baseando-se em dados filogenéticos, Smith et al. (2006) propuseram uma nova classificação para Pteridaceae. Nesta classificação incluíram as famílias ou subfamílias, Acrostichaceae, Actiniopteridaceae, Adiantaceae (Adiantoideae), Anopteraceae, Anthrophyaceae, Ceratopteridaceae,
Cheilanthaceae (Cheilanthoideae), Cryptogrammaceae, Hemionitidaceae, Negripteridaceae, Parkeriaceae, Platyzomataceae, Sinopteridaceae, Taenitidaceae (Taenitidoideae) e Vittariaceae em Pteridaceae.

A família é composta por cerca de 50 gêneros com aproximadamente 950 espécies (Smith et al. 2006). Apresenta ampla distribuição, principalmente nos trópicos e dos cerca de 50 gêneros mencionados 11 são restritos ao Novo Mundo (Prado et al. 2007).

No Brasil são poucos os trabalhos já desenvolvidos de cunho taxonômico, sendo os mais completos aqueles restritos às floras locais como, por exemplo, Sehnem (1972), Windisch \& Nonato (1999), Rodrigues-Jr. (2000), Pietrobom \& Barros (2002), Nonato \& Windisch (2004) e Prado (1992; 1997; 2004; 2005a,b,c). E específico para um gênero, têm-se Tryon (1962), Brade (1965a,b), Prado \& Windisch (2000) e Winter et al. (2007). E publicações de novos táxons, como Prado (1993; $2000 ; 2001 ; 2003)$. Para a Região Norte foi desenvolvido, até o presente estudo o de Prado (2005a) para a flora da Reserva Ducke (Amazonas) e para o estado do Pará ainda não foi desenvolvido nenhum estudo específico para a família.

Desta forma, o presente trabalho tem como objetivo fornecer chaves de identificação dos gêneros e espécies, bem

\footnotetext{
Parte da Dissertação de Mestrado do primeiro Autor

2 Rede CTPetro Amazônia, Belém, PA, Brasil

3 Museu Paraense Emílio Goeldi, Coordenação de Botânica, Belém, PA, Brasil

4 Autor para correspondência: macielbio@yahoo.com.br
} 
como informações taxonômicas sobre as espécies da família Pteridaceae ocorrentes no Campo Experimental da Embrapa Amazônia Oriental e contribuir com o conhecimento sobre a distribuição geográfica das espécies.

\section{Material e métodos}

O Campo Experimental da Embrapa Amazônia Oriental, localiza-se no município de Moju, no km 30 da Rodovia PA-150, situado entre as seguintes

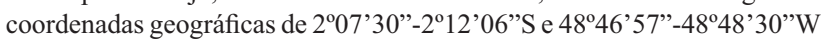
Gr. (Serrão et al. 2003; Oliveira et al. 2006).

Abrange um total de 1059ha (Oliveira et al. 2006), com cobertura vegetal predominante de floresta de terra firme e outra de floresta de igapó (IBGE 1992), ambas as formações encontram-se em estado alterado. A temperatura média anual varia entre $25^{\circ} \mathrm{C}$ e $27^{\circ} \mathrm{C}$ com chuvas anuais de $2.000 \mathrm{~mm}$ a $3.000 \mathrm{~mm}$ (Oliveira et al. 2006).

Foram realizadas coletas aleatórias durante três expedições à área de estudo, durante os meses de agosto e dezembro de 2006 e setembro de 2007 , com cinco dias de coletas em cada expedição. Com o objetivo de explorar os mais diferentes tipos de ambientes, como áreas de terra firme, trilhas no interior da mata e áreas alagadas (floresta de igapó).

A herborização do material coletado seguiu a metodologia padrão para plantas vasculares, segundo Fidalgo \& Bononi (1989) e Windisch (1992) como técnicas detalhadas para o grupo.

As identificações dos espécimes da família foram realizadas com base em Kramer (1978), Tryon \& Tryon (1982), Tryon \& Stolze (1989), Lellinger (1991), Moran \& Yatskievych (1995), Smith \& Lellinger (1995), Cremers (1997), Mickel \& Smith (2004) e Prado (2005a).

As diagnoses dos táxons foram elaboradas a partir do exame dos espécimes coletados no Campo Experimental da Embrapa e seguem os termos propostos por Lellinger (2002), com algumas modificações.

A circunscrição aceita neste trabalho para a família e os gêneros de Pteridaceae segue Smith et al. (2006). Os nomes dos autores dos táxons foram abreviados segundo Pichi-Sermolli (1996).
O material testemunho foi depositado no Herbário MG, do Museu Paraense Emilio Goeldi, com duplicatas enviadas para os herbários SP e MBM (siglas segundo o Index Herbariorum).

Os dados referentes à distribuição geográfica dos táxons foram baseados em Tryon \& Stolze (1989), Smith \& Lellinger (1995), Moran \& Yatskievych (1995) e Mickel \& Smith (2004). A distribuição das espécies nos Estados brasileiros é apresentada em ordem alfabética e está baseada nas seguintes referências (Hieronymus 1909; Sampaio 1916, 1930; Brade 1940, 1947; Braga 1951; Sehnem 1959, 1972; Tryon \& Conant 1975; Windisch 1979; Mori et al. 1983; Peixoto 1984; Krieger \& Camargo 1985; Nauman 1985; Smith 1990; Felix et al. 1996; Labiak \& Prado 1998; Bastos \& Cutrim 1999; Windisch \& Tryon 2001; Barros et al. 2002; Melo \& Salino 2002; Nonato \& Windisch 2004; Paciência \& Prado 2004; Rodrigues et al. 2004; Prado 2005a,c; Pietrobom \& Barros 2002, 2006; Boldrin \& Prado 2007; Fernandes et al. 2007; Maciel et al. 2007; Winter et al. 2007).

Para a análise da distribuição geográfica das espécies estudadas, foram adotados os padrões de distribuição propostos por Parris (2001), Moran \& Smith (2001) e Schwartsburd \& Labiak (2007) com pequenas modificações, enquadrando as espécies nas seguintes categorias: (I) Circum-Antártica espécies presentes na América, África, Ásia e/ou Oceania; (II) Atlântica - espécies presentes na América, África e eventualmente ilhas do Oceano Atlântico; (III) Pacífica - espécies presentes na América, Ásia e/ou Oceania; (IV) Americana - espécies presentes nas Américas do Sul, Central e eventualmente do Norte; (V) Sul-Americana - espécies presentes apenas nos países da América do Sul; (VI) Restrita à região amazônica - espécie que no Brasil distribui-se apenas na região amazônica.

\section{Resultados e discussão}

Pteridaceae Reichb., Hand. Nat. Pflanz. 138. 1837.

A representatividade da família para a flora pteridofítica do Pará é de 13 gêneros e cerca de 54 espécies. Na flora estudada foram registrados oito gêneros e 14 espécies.

Chave para os gêneros de Pteridaceae ocorrentes no Campo Experimental da Embrapa Amazônia Oriental, Pará

1. Plantas epífitas.

2. Lâmina pinatífida, multifurcada ou subflabeliforme; venação livre, nervuras simples ou furcadas

2. Lâmina inteira, linear, oblanceolada ou elíptica; venação anastomosada.

3. Soros lineares e submarginais, paralelos à margem da lâmina; lâmina linear.

4. Lâmina com uma fileira de aréolas entre a costa e a margem. .. 8. Vittaria

4. Lâmina com 3-5 fileiras de aréolas entre a costa e a margem. 3.Ananthacorus

3. Soros ao longo das nervuras, não paralelos à margem da lâmina ou subacrosticóides; lâmina oblanceolada ou elíptica.

5. Soros subacrosticóides, esporângios solitários ou em pequenos grupos sobre e entre as nervuras; caule longo-reptante; frondes espaçadas 4. Anetium

5. Soros distintos, esporângios dispostos ao longo e somente sobre as nervuras; caule curto-reptante; frondes geralmente fasciculadas 7. Polytaenium

1. Plantas terrestres ou anfíbias.

6. Esporângios marginais; margens dos segmentos férteis modificadas como um falso indúsio ...2. Adiantum

6. Esporângios abaxiais ao longo das nervuras ou cobrindo a superfície laminar; margem dos segmentos férteis não modificada como um falso indúsio.

7. Venação anastomosada; soros acrosticóides; pinas sem cera branca ou amarelada na superfície abaxial

7. Venação livre ou furcada; soros sobre as nervuras, não acrosticóides; pinas com cera branca ou amarelada na superfície abaxial.

6. Pityrogramma

\section{Acrostichum L., Sp. Pl. 2: 1067. 1753.}

Gênero com distribuição pantropical, composto por três espécies, sendo que uma é Americana, uma Australasiana e uma é pantropical (Mickel \& Smith 2004). Na flora do estado do Pará são conhecidas para o gênero duas espécies Acrostichum aureum L. e A. danaeifolium Langsd. \& Fisch. No Campo Experimental da Embrapa apenas uma espécie foi registrada. 
Acrostichum é facilmente reconhecido por suas grandes frondes (1,5-4 m comprimento), 1-pinada, com cerca de 20 a 60 pares de pinas e venação reticulada. Os soros são acrosticóides, as paráfises e os esporângios cobrindo densamente toda a superfície abaxial das pinas (Moran 1995a). As espécies são freqüentemente confundidas devido as suas diferenças sutis (Mickel \& Smith 2004). Acrostichum cresce tipicamente em habitats salobros ou salinos ao longo das costas (Moran 1995a).

\subsection{Acrostichum aureum L., Sp. Pl. 2: 1069. 1753.}

Fig. 1

Plantas terrestres em áreas alagadas, anfíbias. Caule com grandes escamas castanho-escuras, ovóides. Frondes até ca. $2 \mathrm{~m}$ compr., eretas ou arqueadas; pecíolo glabro, freqüentemente com curtos "espinhos" (pinas abortivas) na porção distal; lâmina subcoriácea a coriácea, adaxialmente glabra, abaxialmente com diminutos tricomas sobre as nervuras e tecido laminar; pinas 11-18,5 cm compr., 2,8-4,5 cm larg., 8-15 pares, não imbricadas, as basais pecioluladas, base aguda a cuneada, ápice geralmente arredondado, margem inteira, cartilaginosa, recurvada, somente os cinco pares de pinas apicais e terminal férteis; raque glabra; venação composta por aréolas costais ao menos 3 vezes mais longas que largas, paralelas à costa, as demais aréolas dispostas em séries oblíquas em relação à costa. Soros acrosticóides, em todas ou somente nas pinas distais; esporângios abaxiais, cobrindo densamente a superfície laminar.

Material examinado: BRASIL. Pará: Moju, ramal da vila Santa Teresinha ca. $02^{\circ} 10^{\prime} 10,8^{\prime \prime} \mathrm{S}-48^{\circ} 42^{\prime} 41,2$ 'W, 06/ XII/2006, S. Maciel \& M.R. Pietrobom 259 (MG).

Espécie com distribuição Pacífica. No Brasil é citada para o Amapá, Amazonas, Ceará, Maranhão, Pará, Pernambuco e Rio de Janeiro. Na área estudada cresce em floresta de terra firme principalmente em área ocasionalmente alagada, bastante ensolarada, junto de Blechnum serrulatum Rich. e Nepholepis biserrata (Sw.) Schott.
Acrostichum aureum segundo Mickel \& Smith (2004) distingui-se de $A$. danaefolium por apresentar somente os últimos cinco pares de pinas apicais e pina terminal férteis, enquanto que em $A$. danaeifolium todas as pinas ficam férteis.

\section{Adiantum L., Sp. Pl. 2: 1094. 1753.}

Gênero com distribuição pantropical, representado por cerca de 200 espécies, mais da metade destas ocorrem na América tropical e poucas extendem-se às regiões temperadas (Mickel \& Smith 2004). Segundo Lellinger \& Prado (2001) existem cerca de 70 espécies na América do Sul. No Brasil estima-se que ocorram 63 espécies (Winter et al. 2007) espécies. Na flora do estado do Pará são conhecidas para o gênero 26 espécies, destas sete ocorrem na área estudada.

Segundo Mickel \& Smith (2004) para agrupar as espécies de Adiantum são considerados importantes os seguintes caracteres: o padrão de ramificação da lâmina (pinada ou imparipinada, com ou sem uma pina terminal conforme), grau de divisão da lâmina (pinada, 2-pinada ou mais dividida), presença ou ausência de idioblastos venulóides (falsa nervura epidérmica), forma dos últimos segmentos (se dimidiado ou flabelado), indumento da lâmina e eixos (com tricomas, escamas ou nenhum), margem da escama (inteira, denticulada ou ciliada), venação (livre ou anastomosada) extremidade das nervuras (denteada ou sinuosa) e presença ou ausência de zonas de articulação na base dos últimos segmentos.

Algumas espécies de Adiantum por possuir os últimos segmentos (pinas ou pínulas) dimidiados, são às vezes erroneamente identificadas como Lindsaea Dryand. No entanto, Adiantum não possui indúsio verdadeiro e seus eixos (pecíolo, raque e raquíola) são circulares, escuros e brilhantes, diferente do observado em Lindsaea, no qual forma indúsio verdadeiro de origem abaxial e os eixos são páleos, esverdeados a castanho-avermelhados, geralmente sulcados ou fortemente angulosos, às vezes com aletas (Moran et al. 1995).

Segundo Prado (2004; 2005a) o gênero caracteriza-se pelo pseudo-indúsio formado pela margem da lâmina recurvada e modificada.

Chave para as espécies de Adiantum L. ocorrentes no Campo Experimental da Embrapa Amazônia Oriental, Pará

1. Lâmina 1-pinada; pinas não dimidiadas; venação anastomosada

2.2. A. dolosum

1. Lâmina 2-pinada; pinas dimidiadas; venação aberta.

2. Caule longo-reptante; lâmina sem idioblastos; raque e raquíola com tricomas eretos apenas na superfície adaxial e glabra na abaxial.

2.7. A. tomentosum

2. Caule curto-reptante; lâmina com idioblastos; raque e raquíola glabras, pubescente ou escamosas.

3. Pínulas abaxialmente glaucas; pecíolo e raque glabros

2.3. A. glaucescens

3. Pínulas mate; pecíolo e raque escamosos ou pubescentes.

4. Escamas do caule com margem ciliada; pínulas $>36$ pares; indúsio com escamas em forma de tricomas com base ramificada

4. Escamas do caule com margem denticulada a inteira; pínulas $<36$ pares; indúsio com tricomas septados ou escassos.

5. Raque adaxialmente com escamas filiformes e na superfície abaxial lanceoladas com margem longo-ciliada; pínulas falcadas. 
5. Raque com escamas uniformes de margem inteira ou denticulada; pínulas retangulares.

6. Escamas do caule, lustrosas, com margem inteira; escamas do pecíolo com margem inteira a ligeiramente denticulada; margem das pínulas estéreis denteadas a rasamente lobadas nos lados acroscópico e distal...... 2.1. A. cajennense

6. Escamas do caule, mate, com margem longo-denticulada; escamas do pecíolo com margem longociliada; margem das pínulas estéreis inteiras a irregularmente denteadas nos lados acroscópico e distal

2.5. A. paraense

\subsection{Adiantum cajennense Willd. ex Klotzsch, Linnaea 18:} 552. 1845.

Fig. 2-4

Plantas terrestres. Caule curto-reptante, com escamas castanho-avermelhadas a escuras, linear-lanceoladas, margem inteira, lustrosas, cobrindo o ápice do caule. Frondes 18,5$86,5 \mathrm{~cm}$ compr., eretas, monomórficas; pecíolo 17,5-49,5 cm compr., castanho-escuro a negro, sulcado adaxialmente, com escamas castanho-avermelhadas, linear, base pectinada, margem inteira a ligeiramente denticulada, persistente; lâmina cartácea, 2-pinada, oval-deltóide, com idioblastos em ambas as superfícies, adaxialmente glabra, abaxialmente com escamas esparsas, castanho-avermelhadas, linear-lanceoladas, com base pectinada; raque densamente escamosa, com escamas uniformes, castanho-avermelhadas, base pectinada, margem inteira a ligeiramente denticulada; pinas 11-22,5 cm compr., linear-lanceoladas, $2-5$ pares, subopostas a alternas; raquíola semelhante à raque; pínulas 1,3-2 cm compr., 0,3-0,5 cm larg., 18-36 pares, mate, retangulares, dimidiadas, base assimétrica, no lado acroscópico largamente cuneada, ápice arredondado, não imbricadas, margem das pínulas estéreis denteadas a rasamente lobadas nos lados acroscópico e distal, margem das pínulas férteis revoluta e modificada em pseudo-indúsios; costa glabra ou com poucas escamas esparsas; venação aberta, nervuras 2 a + vezes furcadas. Soros 3-8 por pínulas, oblongos, dispostos ao longo da margem acroscópica; indúsio com margem erosa, tricomas bem escassos.

Material selecionado: BRASIL. Pará: Moju, trilha Murça Pires ca. $02^{\circ} 11^{\prime} 0,13^{\prime \prime S}-48^{\circ} 47^{\prime} 45,1^{\prime \prime} \mathrm{W}, 4 / \mathrm{VIII} / 2006$, S. Maciel et al. 170 (MG, SP); ramal da vila Santa Teresinha ca. $02^{\circ} 10^{\prime} 10,8^{\prime \prime} \mathrm{S}-48^{\circ} 42^{\prime} 41,2^{\prime \prime} \mathrm{W}, 6 / \mathrm{XII} / 2006$, S. Maciel \& M.R. Pietrobom 267 (MG, SP); ramal da vila Santa Teresinha ca. $02^{\circ} 09^{\prime} 54,4^{\prime \prime} \mathrm{S}-48^{\circ} 47^{\prime} 17,7^{\prime \prime} \mathrm{W}, 6 / \mathrm{XII} / 2006, S$. Maciel \& M.R. Pietrobom 308 (MG, SP); trilha Normália ca. $02^{\circ} 10^{\prime} 13,3$ "S-48 $47^{\circ} 46,9^{\prime \prime W}, 27 / \mathrm{VIII} / 2007$, S. Maciel et al. 310 (MG, SP).Espécie com distribuição Americana. No Brasil é restrita à região amazônica, sendo citada para o Acre, Amazonas e Pará. Na área estudada cresce no interior da mata de terra firme e de igapó, nas trilhas e no ramal de acesso a vila Santa Teresinha.

Prado (2005a) caracteriza esta espécie pela presença de escamas com base pectinada sobre o indúsio. Os espécimes do Campo Experimental da Embrapa também podem ser caracterizados pelas escamas do caule lustrosas de margem inteira e pínulas estéreis denteadas a rasamente lobadas nos lados acroscópico e distal.

\subsection{Adiantum dolosum Kunze, Linn. 21: 219. 1848.} Fig. 5

Plantas terrestres. Caule curto-reptante, com escamas castanho-avermelhadas a escuras, lineares, margem inteira a denteada, lustrosas, cobrindo o ápice do caule. Frondes 11-52 cm compr., eretas, monomórficas; pecíolo 6-31,5 cm compr., castanho-escuro a negro, sulcado adaxialmente, coberto com escamas castanho-avermelhadas, caducas; lâmina cartácea a subcoriácea, 1-pinada, triangular, oblonga, com idioblastos em ambas as superfícies, abaxialmente com escamas esparsas, castanho-claras, linear-lanceoladas, base pectinada, margem inteira; raque persistentemente escamosa, escamas lineares, levemente ciliadas a denteadas na margem; pinas 3,4-10,5 cm compr., lanceoladas, deltóideslanceoladas, 2-4 pares, alternas, falcadas, acuminadas, a base obliqua, amplamente cuneada, e paralela a raque acroscopicamente, não dimidiadas, margens denteadas na porção distal; costa com escamas escassas; venação anastomosada, visível em ambas as superfícies. Soros contínuos, lineares, dispostos ao longo de ambas às margens; indúsio com margem erosa, glabro.

Material selecionado: BRASIL. Pará: Moju, trilha Martius ca. 02 ${ }^{\circ} 10^{\prime} 28,9^{\prime \prime}$ S- $48^{\circ} 47^{\prime} 42,9^{\prime \prime} \mathrm{W}, 3 / \mathrm{VIII} / 2006, S$. Maciel et al. 130 (MG, SP); ramal da Vila Santa Teresinha ca. $02^{\circ} 09^{\prime} 35,5^{\prime \prime} \mathrm{S}-48^{\circ} 47^{\prime} 20,9^{\prime \prime} \mathrm{W}, 4 / \mathrm{XII} / 2006$, S. Maciel \& M.R. Pietrobom 198 (MG, SP); margem do rio Carioca ca. 02 $08^{\circ} 47,7^{\prime \prime} \mathrm{S}-48^{\circ} 48^{\prime} 12,1$ 'W, 05/XII/2006, S. Maciel \& M.R. Pietrobom 237 (MG, SP); margem do rio Santa Teresinha, ca. 02 $09^{\prime} 36,6$ "S-4846'55,1”W, 6/XII/2006, S. Maciel \& M.R. Pietrobom 256 (MG, SP).

Espécie com distribuição Sul-Americana. No Brasil é citada para Alagoas, Amazonas, Bahia, Ceará, Espírito Santo, Minas Gerais, Pernambuco e São Paulo. Neste trabalho é referida pela primeira vez para o Pará. $\mathrm{Na}$ área estudada cresce no interior da mata de terra firme ao longo das trilhas ou canaletas, na margem do rio em igapó ou nos ramais que cortam o Campo Experimental da Embrapa.

Adiantum dolosum é a única espécie ocorrente na área estudada que apresenta a lâmina 1-pinada com escamas esparsas na superfície abaxial. Os eixos são escamosos, as pinas são falcadas, acuminadas, não dimidiadas, a venação é anastomosada e os soros são contínuos em ambas às margens da lâmina. Pode ser confundida com Adiantum lucidum (Cav.) Sw. (quando a lâmina for 1-pinada), pelo pecíolo coberto com escamas castanho-avermelhadas e soros contínuos ao longo da margem da lâmina (Cremers 1997). Entretanto, 
A. lucidum apresenta a lâmina bipinada (dividida mais de uma vez) na base e de 8 a 11 pares de pinas (Kramer 1978).

\subsection{Adiantum glaucescens Klotzsch, Linnaea 18: 552. 1844.} Fig. 6

Plantas terrestres. Caule curto-reptante, escamas castanho-escuras, triangular-lanceoladas, biauriculadas na base, margem denteada, mate, cobrindo o ápice do caule. Frondes 18,5-73,5 cm compr., eretas, monomórficas; pecíolo 10,5-46,5 cm compr., negro, não sulcado, glabro ou ocasionalmente com poucas escamas somente na base; lâmina cartácea, triangular, 2-pinada, com idioblastos em ambas as superfícies, glabra; raque negra, glabra; pinas $5,2-15 \mathrm{~cm}$ compr., elípticas, $2-5$ pares, alternas, pecioluladas; raquíola semelhante à raque; pínulas $1,2-2,3 \mathrm{~cm}$ compr., $0,5-0,9 \mathrm{~cm}$ larg., 5-17 pares, retangulares, glaucas abaxialmente, dimidiadas, curvadas para o ápice, base assimétrica, acroscopicamente truncada, não ou ligeiramente imbricadas, margem das pínulas estéreis irregularmente denteadas, ápice da pínula estéril agudo e da fértil arredondado, margem das pínulas férteis revoluta e modificada em pseudo-indúsios; costa glabra; venação aberta, nervuras de $2 \mathrm{a}+$ vezes furcadas. Soros 3-9 por pínulas, oblongos, dispostos ao longo das margens acroscópica e distal; indúsio com margem erosa, glabro.

Material selecionado: BRASIL. Pará: Moju, trilha Murça Pires ca. $02^{\circ} 11^{\prime} 0,13^{\prime}$ 'S-48 47'45,1”'W, 4/VIII/2006, S. Maciel et al. 164 (MG, SP); ramal da vila Santa Teresinha ca. 02 ${ }^{\circ} 09^{\prime} 54,4$ "S-4847'17,7”'W, 4/XII/2007, S. Maciel \& M.R. Pietrobom 192 (MG, SP); ramal da vila Santa Teresinha ca. $02^{\circ} 10^{\prime} 10,8^{\prime \prime} \mathrm{S}-48^{\circ} 42^{\prime} 41,2^{\prime \prime} \mathrm{W}, 6 / \mathrm{XII} / 2006$, S. Maciel \& M.R. Pietrobom 266 (MG, SP); trilha bacurizal ca. $02^{\circ} 11^{\prime} 54,2$ "S4847'48,6”W, 7/XII/2006, S. Maciel \& M.R. Pietrobom 274 (MG, SP).

Espécie com distribuição Sul-Americana. No Brasil é citada para o Amazonas, Minas Gerais, Pará, Pernambuco, Rio de Janeiro e Roraima. Na área estudada cresce em floresta de terra firme e igapó nas margens dos rios, no interior da mata e próxima às trilhas.

Adiantum glaucescens caracteriza-se pelo pecíolo e raque glabros, a lâmina apresenta idioblastos em ambas as superfícies, as pínulas são glaucas e glabras na face abaxial.

2.4. Adiantum multisorum A. Samp. in Hoehne, Relat. Commiss. Linhas. Estrateg. Mato Grosso-Amazonas 5(Bot. pt. 7): 11, pl. 1, f. 1. 1916.

Fig. 7-8

Plantas terrestres. Caule curto-reptante, com escamas linear-lanceoladas, centro negro e margem castanho-clara, ciliada, lustrosas, cobrindo o ápice do caule. Frondes 36,5$100 \mathrm{~cm}$ compr., eretas, monomórficas; pecíolo 19-71,5 cm compr., castanho-escuro a negro, adaxialmente sulcado, escamoso, com escamas castanho-claras, linear-lanceoladas, margem ciliada, persistentes; lâmina cartácea, triangular, 2-pinada, com idioblastos em ambas as superfícies, adaxial- mente com algumas poucas escamas esparsas, abaxialmente escamosa, com escamas castanho-claras, linear-lanceoladas, margem inteira; raque densamente escamosa, com escamas castanho-claras, linear-lanceoladas, margem fortemente ciliada; pinas 10-30 cm compr., linear-elípticas, 3-7 pares, alternas, pecioluladas; raquíola semelhante à raque; pínulas 0,9-2,4 cm compr., 0,4-0,7 cm larg., geralmente $>36$ pares, mate, retangulares, ocasionalmente falcadas, dimidiadas, base assimétrica, ápice acuminado, não ou ligeiramente imbricadas, margem das pínulas estéreis inteiras a irregular e espaçadamente denteadas no lado acroscópico, margem distal denteada, margem das pínulas férteis revoluta e modificada em pseudo-indúsios; costa glabra; venação aberta, nervuras de 2 a + vezes furcadas. Soros 3-11 por pínulas, pequenos, oblongos, muito próximos, dispostos ao longo das margens acroscópica e distal; indúsio com margem erosa com escamas em forma de tricomas com base ramificada.

Material selecionado: BRASIL. Pará: Moju, trilha Ducke ca. $02^{\circ} 11^{\prime} 0,19^{\prime}$ 'S-48 $47^{\prime}$ 45, 1'W, 2/VIII/2006, S. Maciel et al. 108 (MG, SP); trilha Murça Pires ca. 02¹1'0,13"S48 47'45,1'W, 4/VIII/2006, S. Maciel et al. 162 (MG, SP); ramal da vila Santa Teresinha ca. $02^{\circ} 08^{\prime} 47,7^{\prime \prime S}$ 48'48'12,1'W, 4/XII/2006, S. Maciel \& M.R. Pietrobom 180 (MG, SP); margem do rio Carioca ca. 0208'47,7'S4848'12,1'W, 5/XII/2006, S. Maciel \& M.R. Pietrobom 211 (MG, SP).

Espécie com distribuição Sul-Americana. No Brasil é restrita a região amazônica, sendo citada até o presente estudo somente para Rondônia. Neste trabalho é referida pela primeira vez para o Pará. $\mathrm{Na}$ área estudada cresce em igapós, nas margens dos rios e no interior da mata de floresta de terra firme.

Além dos caracteres apresentados na chave, Adiantum multisorum pode ser distinguida por apresentar muitos soros pequenos. E ainda, sobre o indúsio há escamas em forma de tricomas com base ramificada e na raque há escamas com margem fortemente ciliada.

2.5. Adiantum paraense Hieron., Hedwigia 48: 233. tab. 11, 10. 1909.

Fig. 9-11

Plantas terrestres. Caule curto-reptante, com escamas lanceoladas, centro negro e margem castanho-clara, margem longo-denticulada, mate, cobrindo o ápice do caule. Frondes $15-81 \mathrm{~cm}$ compr., eretas, monomórficas; pecíolo 8,5-53 cm compr., castanho-escuro a negro, sulcado abaxialmente, com escamas basalmente esparsas a distalmente agregadas, castanho-claras, linear-lanceoladas, base pectinada, margem longo-ciliada, persistentes; lâmina cartácea, triangular, 2-pinada, com idioblastos em ambas as superfícies, abaxialmente com escamas esparsas, linear-lanceoladas, castanho-claras, base pectinada, margem inteira; raque com escamas uniformes de margem denticulada a curto ciliada e tricomas; pinas 6-18,5 cm compr., linear-lanceoladas, 1-4 pares, alternas, 
peciolulada; raquíola semelhante à raque; pínulas $1-2,3 \mathrm{~cm}$ compr., 0,4-0,6 cm larg., 12-25 pares, mate, retangulares, dimidiadas, base assimétrica, acroscopicamente truncada, ápice arredondado, não ou ligeiramente imbricadas, margem das pínulas estéreis inteiras a irregularmente denteadas nos lados acroscópico e distal, margem das pínulas férteis revoluta e modificada em pseudo-indúsios; costa com poucas escamas esparsas; venação aberta, nervuras de $2 \mathrm{a}+$ vezes furcadas. Soros 7-11 por pínulas, oblongos, dispostos ao longo das margens acroscópica e distal; indúsio com margem erosa, com tricomas septados.

Material selecionado: BRASIL. Pará: Moju, trilha Martius ca. 02 10 '28,9”S-48 47'42,9”'W, 3/VIII/2006, S. Maciel et al. 151 (MG, SP); ramal da vila Santa Teresinha ca. $02^{\circ} 09^{\prime} 54,4^{\prime \prime S}-48^{\circ} 47^{\prime} 17,7^{\prime \prime} \mathrm{W}, 4 / \mathrm{XII} / 2006$, S. Maciel \& M.R. Pietrobom 187 (MG, SP); ramal da vila Santa Teresinha ca. $02^{\circ} 09^{\prime} 54,4{ }^{\prime} \mathrm{S}-48^{\circ} 47^{\prime} 17,7$ 'W, 4/XII/2006, S. Maciel \& M.R. Pietrobom 193 (MG, SP); trilha bacurizal ca. $02^{\circ} 11^{\prime} 54,2^{\prime}$ 'S-48 47'48,6”'W, 7/XII/2006, S. Maciel \& M.R. Pietrobom 276 (MG, SP); ramal da vila Santa Teresinha ca. $02^{\circ} 08^{\prime} 47,7^{\prime}$ S-4848'12, 1'W, 4/XII/2006, S. Maciel \& M.R. Pietrobom 305 (MG).

Espécie com distribuição Sul-Americana. No Brasil é restrita à região amazônica, sendo citada para o Amazonas, Pará e Rondônia. $\mathrm{Na}$ área de estudo cresce em ambiente úmido de solo argiloso, no interior da mata de terra firme e de igapó, nas margens dos rios, geralmente coletada e observada junto de Adiantum multisorum.

Adiantum paraense pode ser reconhecida pelas escamas do caule mate com margem longo-denticulada, as escamas do pecíolo apresentam a margem longo-ciliada. As pínulas estéreis são inteiras a irregularmente denteadas nos lados acroscópico e distal. E ainda sobre o indúsio há tricomas septados.

\subsection{Adiantum tetraphyllum Humb. \& Bonpl. ex Willd., Sp.}

Pl. ed. 4, 5: 441. 1810.

Fig. 12-14

Plantas terrestres. Caule curto-reptante, com escamas castanho a castanho-escuras, linear-lanceoladas, margem denticulada, lustrosas. Frondes $44-79 \mathrm{~cm}$ compr., eretas, monomórficas; pecíolo 27,5-39,5 cm compr., atropurpúreo a castanho-escuro, sulcado abaxialmente, glabro a persistentemente escamoso, as escamas castanhos, fibrilosas, persistentes; lâmina cartácea, 2-pinada, com idioblastos em ambas as superfícies, ovóide-deltada a ovóide-oblonga, ocasionalmente com muitas a poucas escamas pequenas e pectinadas; raque adaxialmente com escamas filiformes, margem e base com projeções irregulares e abaxialmente lanceoladas com margem longo-ciliada; pinas $10,5-17,5 \mathrm{~cm}$ compr., elíptica-lanceoladas, 1-2 pares, alternas, atenuadas no ápice em direção a pina terminal pecioluladas; raquíola semelhante à raque; pínulas $1,5-2,3 \mathrm{~cm}$ compr., $0,4-0,6 \mathrm{~cm}$ larg., ocasionalmente retangulares, geralmente falcadas,
15-27 pares, mate, dimidiadas, imbricadas ou não, escamosa abaxialmente, sésseis a subsésseis, margem da pínula estéril serreada, assimétrica, ápice acuminado a obtuso, margem das pínulas férteis revoluta e modificada em pseudo-indúsios; costa glabra; venação aberta, nervuras $2 \mathrm{a}+$ vezes furcadas. Soros 2-8 por pínulas, oblongos, dispostos na margem acroscópica e ocasionalmente nas distais; indúsio com margem inteira a erosa, com tricomas septados.

Material selecionado: BRASIL. Pará: Moju, ramal da vila Santa Teresinha ca. $02^{\circ} 08^{\prime} 47,7^{\prime \prime} \mathrm{S}-48^{\circ} 48^{\prime} 12,1^{\prime \prime} \mathrm{W}, 4 /$ XII/2006, S. Maciel \& M.R. Pietrobom 181 (MG, SP); trilha bacurizal ca. $02^{\circ} 11^{\prime} 54,2^{\prime \prime} \mathrm{S}-48^{\circ} 47^{\prime} 33,6^{\prime}$ 'W, 7/XII/2006, S. Maciel \& M.R. Pietrobom 287 (MG, SP); trilha bacurizal ca. $02^{\circ} 10^{\prime} 50,1^{\prime \prime} \mathrm{S}-48^{\circ} 46^{\prime} 28,3^{\prime}$ 'W, 07/XII/2006, S. Maciel \& M.R. Pietrobom 293 (MG, SP).

Espécie com distribuição Sul-Americana. No Brasil é citada para o Amapá, Amazonas, Ceará, Distrito Federal, Goiás, Mato Grosso, Minas Gerais, Pará, Paraná, Pernambuco, Rio de Janeiro, Roraima e Santa Catarina. Na área estudada cresce principalmente no interior da mata de terra firme junto às trilhas.

Adiantum tetraphyllum caracteriza-se por apresentar na superfície adaxial da raque, escamas filiformes de margem e base com projeções irregulares e na superfície abaxial as escamas são lanceoladas com margem longo-ciliada. As pínulas são falcadas, escamosas abaxialmente e as margens das pínulas estéreis são serreadas.

2.7. Adiantum tomentosum Klotzsch, Linnaea 18: 553. 1845.

Fig. 15-16

Plantas terrestres. Caule longo-reptante, com escamas castanho-claras, linear-lanceoladas, base biauriculada, margem inteira a denticulada, lustrosas. Frondes $52-153 \mathrm{~cm}$ compr., eretas, monomórficas; pecíolo 29-84,5 cm compr., castanho-escuros, sulcado abaxialmente, com escamas iguais às do caule mais concentradas na base e curtos tricomas eretos, castanho-claros; lâmina cartácea, 2-pinada (ocasionalmente 1-pinada), sem idioblastos, oval-deltóide a oval-oblonga, glabra; raque com tricomas ca. $1 \mathrm{~mm}$ compr., eretos, apenas na superfície adaxial e lateral, glabra abaxialmente; pinas 15-32 cm compr., 3-11 linear-lanceoladas, pares, alternas, pecioluladas; raquíola semelhante à raque; pínulas 1,4-2,6 cm compr., 0,5-1,0 cm larg., retangulares, 18-34 pares, dimidiadas, acroscopicamente truncada, ápice arredondado, em geral ligeiramente imbricadas, margem das pínulas estéreis regularmente serreada a crenulada no lado acroscópico e distal, margem das pínulas férteis revoluta e modificada em pseudo-indúsios; costa glabra; venação aberta, nervuras 2 a + vezes furcadas. Soros ca. 24 por pínula, oblongos, dispostos na margem acroscópica; indúsio com margem inteira a erosa, glabro.

Material examinado: BRASIL. Pará: Moju, trilha Martius, ca. $02^{\circ} 10^{\prime} 28,9^{\prime \prime} S-48^{\circ} 47^{\prime} 42,9^{\prime \prime} \mathrm{W}, 3 / \mathrm{VIII} / 2006$, S. Maciel et al. 


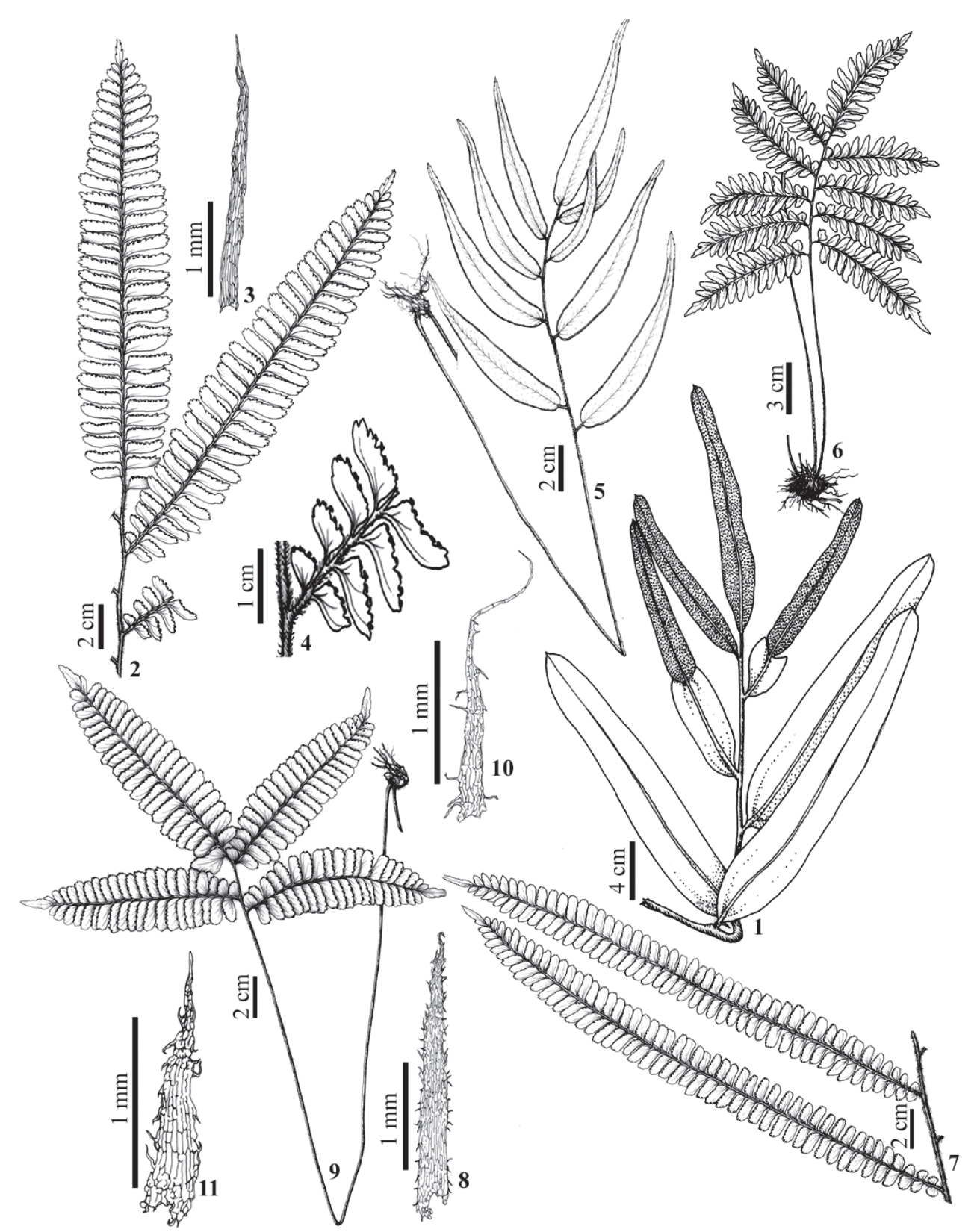

Figuras 1-11. Acrostichum aureum L. 1. Pinas (Maciel \& Pietrobom 259). Adiantum cajennense Willd. ex Klotzsch. 2. Pinas. 3. Escama do caule. 4. Pínulas (2, 4. Maciel \& Pietrobom 267; 3. Maciel \& Pietrobom 308). Adiantum dolosum Kunze. 5. Hábito (Maciel \& Pietrobom 256). Adiantum glaucescens Klotzsch. 6. Hábito (Maciel \& Pietrobom 260). Adiantum multisorum A. Samp. 7. Pinas. 8. Escama do caule (Maciel et al. 108). Adiantum paraense Hieron. 9. Hábito. 10. Escama do pecíolo. 11. Escama do caule (9. Maciel \& Pietrobom 276; 10-11. Maciel \& Pietrobom 305).

133 (MG, SP); ramal da vila Santa Teresinha ca. 02 09'35,5”S484'20,9’'W, 4/XII/2006, S. Maciel \& M.R. Pietrobom 201 (MG, SP); margem do rio Carioca ca. 02 $08^{\prime} 47,7^{\prime \prime}$ S4848'12,1'W, 5/XII/2006, S. Maciel \& M.R. Pietrobom 229 (MG, SP); trilha bacurizal ca. $02^{\circ} 11^{\prime} 54,2^{\prime \prime} \mathrm{S}-48^{\circ} 47^{\prime} 33,6^{\prime \prime} \mathrm{W}, 7 /$ XII/2006, S. Maciel \& M.R. Pietrobom 285 (MG, SP).

Espécie com distribuição Sul-Americana. No Brasil é restrita à região amazônica, sendo citada para o Acre, Amazonas e Pará. $\mathrm{Na}$ área estudada cresce no interior da mata em igapó, na margem dos rios e em canaletas.
Adiantum tomentosum caracteriza-se pelo caule longoreptante, o pecíolo apresenta curtos tricomas eretos e escamas na base, lâmina sem idioblastos, a raque e a raquíola possui tricomas de cerca de $1 \mathrm{~mm}$ de comprimento apenas na superfície adaxial e o indúsio é desprovido de escamas ou tricomas. Segundo Tryon \& Stolze (1989) também pode ser reconhecida pela presença de tricomas nas laterais da raque.

3. Ananthacorus Underw. \& Maxon in Maxon, Contr. U.S. Natl. Herb. 10: 487. 1908. 
Gênero monoespecífico que ocorre na América Central, América do Sul e Caribe (Antilhas) (Crane 1997).

Ananthacorus difere de Vittaria Sm. por apresentar 2-3 séries de aréolas (às vezes 4 ou 5) entre a costa e a margem da lâmina (Mickel \& Smith 2004) e a lâmina mais larga (1$1,5 \mathrm{~cm}$ larg.). E ainda, o caule é esponjoso, as frondes são pendentes, a lâmina é simples, inteira e glabra. Os soros são lineares, paralelos às margens da lâmina e as paráfises apresentam células apicais filiformes.

\subsection{Ananthacorus angustifolius (Sw.) Underw. \& Maxon} in Maxon, Contr. U.S. Natl. Herb. 10: 487. 1908.

Fig. 17-18

Plantas epífitas. Caule curto-reptante, dorsoventral, esponjoso, com escamas estreitamente castanho-escuras, lanceoladas, margem denticulada, mate, clatradas. Frondes 3,5-35 cm compr., 1-1,5 cm larg., fasciculadas a moderadamente espaçadas, pendentes; pecíolo pálido ou concolor, muito reduzido ou ausente, aplanado; lâmina cartácea a coriácea, linear a linear-elíptica, simples, inteira, margem plana, glabra; venação anastomosada, com 3-5 fileiras de aréolas alongadas entre a costa e a margem, sem vênulas livres inclusas, nervuras geralmente inconspícuas. Soros lineares, contínuos ou não, paralelos às margens da lâmina, formados em uma comissura submarginal; paráfises com célula apical filiforme; esporos monoletes.

Material examinado: BRASIL. Pará: Moju, trilha Ducke ca. $02^{\circ} 11^{\prime} 0,19^{\prime}$ 'S-48 $47^{\prime} 45,1$ 'W, 2/VIII/2006, S. Maciel et al. 122 (MG, MBM); trilha Martius ca. $02^{\circ} 10^{\prime} 28,9^{\prime} \mathrm{S}-48^{\circ} 47^{\prime} 42,9^{\prime \prime} \mathrm{W}, 3 / \mathrm{VIII} / 2006$, S. Maciel et al. 144 (MG); ramal da vila Santa Teresinha ca. 02009'35,5"S-48'47'20,9'W, 4/XII/2006, S. Maciel \& M.R. Pietrobom 199 (MG); margem do rio Carioca ca. $02^{\circ} 08^{\prime} 47,7$ 'S-48 48'12,1”W, 5/XII/2006, S. Maciel \& M.R. Pietrobom 233 (MG).

Espécie com distribuição Americana. No Brasil é citado para o Acre, Alagoas, Amapá, Amazonas, Bahia, Ceará, Espírito Santo, Mato Grosso, Minas Gerais, Pará, Paraíba, Paraná, Pernambuco, Rio de Janeiro, Rio Grande do Sul, Rondônia, Roraima, Santa Catarina e São Paulo. Na área estudada cresce no interior da mata de terra firme, próximo aos rios ou igapós em ambiente úmido.

4. Anetium Splitg., Tijdschr. Natuurl. Gesch. Physiol. 7: 395. 1840.

Gênero monoespecífico e amplamente espalhado no neotrópico (Mickel \& Smith 2004).

De acordo com Crane (1997) Anetium é um gênero irmão de Polytaenium Desv., e difere pelos esporângios dispostos individualmente ou em pequenos grupos isolados entre e sobre as nervuras e as frondes são mais espaçadas no caule longo-reptante e pendentes (Mickel \& Smith 2004).
4.1. Anetium citrifolium (L.) Splitg., Tijdschr. Natuurl. Gesch. Physiol. 7: 395. 1840.

Fig. 19-20

Plantas epífitas. Caule longo-reptante, dorsoventral, escamoso, com escamas lanceoladas, margem denticulada, lustrosas, clatradas. Frondes 5,3-9,5 cm compr., 1,2-2,7 cm larg., espaçadas, pendentes; pecíolo ausente ou muito reduzido, glabro; lâmina subcoriácea, oblanceolada a estreitamente elíptica, simples, inteira, base freqüentemente atenuada, ápice agudo a acuminado, glabra; costa não percorrente, estendendo-se até ca. $2 / 3$ do comprimento da lâmina; venação anastomosada, com várias fileiras de aréolas entre a costa e a margem, aréolas alongadas, hexagonais, sem vênulas livres inclusas, tendendo a ficar oblíquas em relação à costa. Soros subacrosticóides; esporângios solitários ou em pequenos grupos sobre e entre as nervuras; esporos triletes.

Material examinado: BRASIL. Pará: Moju, margem do rio Carioca ca. $02^{\circ} 08^{\prime} 47,7^{\prime \prime} \mathrm{S}-48^{\circ} 48^{\prime} 12,1$ ' 'W, 5/XII/2006, $S$. Maciel \& M.R. Pietrobom 239 (MG).

Espécie com distribuição Americana. No Brasil é citado para o Acre, Alagoas, Amapá, Amazonas, Bahia, Mato Grosso, Pará, Pernambuco, Santa Catarina e São Paulo. Na área estudada cresce principalmente no interior da mata de terra firme e/ou próximo a rodovia.

\section{Hecistopteris J. Sm., London J. Bot. 1: 193. 1842.}

Hecistopteris é reconhecido facilmente pelo seu tamanho pequeno, frondes pinatífidas ou furcando no ápice, raízes prolíferas e venação livre (Moran 1995b; Mickel \& Smith 2004). Os soros são alongados ao longo das nervuras, somente na porção apical da lâmina. As plantas formam colônias através de raízes prolíferas, sendo típico encontrar várias plantas unidas em uma única raiz (Moran 1995b).

Gênero considerado por mais de 150 anos monoespecífico, mas recentemente duas novas espécies foram descritas uma para o Equador (H. pinnatifida R.C. Moran \& B. Øllg.) e a outra espécie (H. kaieteurensis Kelloff \& Mckee) para a Guiana e Brasil (Mickel \& Smith 2004). Na flora do Estado do Pará são conhecidas para o gênero duas espécies e na área estudada apenas uma.

\subsection{Hecistopteris pumila (Spreng.) J. Sm., London J. Bot.} 1: 193.1842.

Fig. 21

Plantas epífitas. Caule com escamas, castanho-claras, linear-lanceoladas, margem denticulada, clatradas, mate, em tufos na base da lâmina. Frondes 0,7-3,3 cm compr., até 1,4 cm larg., eretas, cespitosas; pecíolo séssil ou subséssil, glabro, geralmente encoberto pelas escamas do caule; lâmina papirácea, subflabeliforme, com idioblastos em ambas as superfícies, últimos segmentos não recurvados, geralmente > $1 \mathrm{~mm}$ larg; venação livre, nervuras simples ou furcadas, uma a cada lobo do ápice da lâmina, geralmente pouco evidentes. Soros alongados, dispostos apenas no ápice da lâmina. 
Material examinado: BRASIL. Pará: Moju, trilha Ducke ca. $02^{\circ} 11^{\prime} 0,19^{\prime \prime}$ S- $48^{\circ} 47^{\prime} 45,1$ 'W, 2/VIII/2006, S. Maciel et al. 127 (MG); margem do rio Carioca ca. $02^{\circ} 08^{\prime} 47,7^{\prime \prime} \mathrm{S}-$ 48 $48^{\prime} 12,1^{\prime \prime W}, 5 / \mathrm{XII} / 2006$, S. Maciel \& M.R. Pietrobom 224 (MG); trilha bacurizal ca. $02^{\circ} 10^{\prime} 50,1^{\prime \prime} \mathrm{S}-48^{\circ} 46{ }^{\prime} 28,3^{\prime \prime} \mathrm{W}$, 7/XII/2006, S. Maciel \& M.R. Pietrobom 299 (MG, MBM).

Espécie com distribuição Americana. No Brasil é citada para o Acre, Amapá, Amazonas, Bahia, Mato Grosso, Minas Gerais, Pará, Paraíba, Paraná, Pernambuco, Rio de Janeiro, Rondônia, Santa Catarina e São Paulo. Na área estudada cresce em arvoretos no interior da mata de terra firme e geralmente junto de Didymoglossum pinnatinervium (Jenm.) Pic. Serm.

Hecistopteris pumila assemelha-se a H. kaieteurensis no tamanho e hábito, diferindo-se desta, principalmente na forma da lâmina subflabeliforme com os últimos segmentos não recurvados. Enquanto que em H. kaieteurensis a lâmina é multifurcada com os últimos segmentos recurvados (Kelloff \& Mckee 1998).

\section{Pityrogramma Link, Handb. Gewächse 3: 19. 1833.}

Gênero pantropical composto por cerca de 17 espécies, com maior diversidade na América tropical (Mickel \& Smith 2004). Na flora do estado do Pará e Campo Experimental da Embrapa é conhecida para o gênero apenas uma espécie.

Pityrogramma caracteriza-se pela presença na lâmina de uma cera branca ou amarelada cobrindo parte da superfície abaxial e pelos esporângios dispostos ao longo das nervuras (Prado 2005a).

\subsection{Pityrogramma calomelanos (L.) Link var. calomelanos,}

Handbuch 3: 20. 1833.

Fig. 22

Plantas terrestres. Caule decumbente a ereto, com escamas castanhas, estreitamente lanceoladas, margem inteira, lustrosas. Frondes 33-94 cm compr., 5-30 cm larg., eretas, monomórficas; pecíolo 15,5-59,5 cm compr., castanho-avermelhado a atropurpúreo, lustroso, com escamas semelhantes às do caule somente na base; lâmina cartácea, lanceolada a ovóidelanceolada, 2-pinado-pinatífida, atenuada em direção ao ápice, glabra em ambas as superfícies, com cera branca ou amarelada somente na superfície abaxial; raque castanho-avermelhada a atropurpúrea, lustrosa, glabra; pinas lanceoladas, 1-pinadas ou as basais 1-pinado-pinatífidas, subopostas a alternas, ápice longo acuminada, pecioluladas; raquíola semelhante à raque; pínulas lanceoladas a elípticas, pecioluladas, as distais com base adnada, ápice agudo a arredondado, margem serreada ou profundamente incisa nas proximais; venação simples ou furcadas. Soros abaxiais, dispostos ao longo das nervuras; esporângios numerosos, junto a uma cera branca ou amarelada.

Material examinado: BRASIL. Pará: Moju, margem da PA-150 ca. $02^{\circ} 10^{\prime} 47,1^{\prime \prime S}-48^{\circ} 47^{\prime} 57,5^{\prime \prime} \mathrm{W}, 4 / \mathrm{VIII} / 2006, S$. Maciel et al. 157 (MG); ramal da vila Santa Teresinha ca. 02 ${ }^{\circ} 09^{\prime} 36,6^{\prime}$ "S-48 46' 55, 1"W, 6/XII/2006, S. Maciel \& M.R. Pietrobom 254 (MG).
Espécie com distribuição Pacífica. É introduzida nos trópicos do Velho Mundo (Moran 1995c). No Brasil, é citada para o Acre, Alagoas, Amapá, Amazonas, Bahia, Ceará, Distrito Federal, Goiás, Maranhão, Mato Grosso, Mato Grosso do Sul, Minas Gerais, Pará, Paraná, Pernambuco, Piauí, Rio de Janeiro, Rio Grande do Sul, Rondônia, Santa Catarina e São Paulo. Na área estudada cresce no interior da mata de terra firme e principalmente em locais bastante alterados como margem de estrada.

Segundo Moran (1995c) Pityrogramma calomelanos var. calomelanos e muito semelhante a $P$. calomelanos var. austroamericana (Domin) Farw., diferindo-se desta, pela presença da cera branca a amarelada na superfície abaxial da lâmina, característica observada nos espécimes coletados no Campo Experimental da Embrapa.

7. Polytaenium Desv., Mém. Soc. Linn. Paris 6: 218. 1827. Gênero composto por 8-10 espécies neotropicais (Crane 1997; Mickel \& Smith 2004). Na flora do estado do Pará são conhecidas para o gênero quatro espécies, destas apenas uma foi registrada na área estudada.

Polytaenium e Antrophyum Kaulf. historicamente tem sido distinguido pela presença de uma costa distinta ou pelo menos proximalmente distinta e no segundo ausência de costa. Em Polytaenium as paráfises são ausentes enquanto que em Antrophyum as paráfises estão presentes. Polytaenium difere de Vittaria por ter mais de um soro em cada lado da costa ou por ter soros contínuos ao longo das nervuras reticuladas (Mickel \& Smith 2004).

7.1. Polytaenium guayanense (Hieron.) Alston, Kew Bull. 314. 1932.

Fig. 23-24

Plantas epífitas. Caule curto-reptante, com escamas estreito-lanceoladas, margem denticulada, clatradas, levemente lustrosas, raízes com muitos tricomas amarelados, formando aspecto esponjoso. Frondes 11,2-35 cm compr., 1,8-4,5 cm larg., pendentes, fasciculadas; pecíolo ausente ou até $3,5 \mathrm{~cm}$ compr., paleáceo abaxialmente, estreitamente alado, glabro; lâmina cartácea a subcoriácea, estreitamente elíptica com os lados quase paralelos, margens planas ou levemente revolutas; costa percorrente, proeminente na face abaxial, esverdeada na base; venação anastomosada, aréolas formando fileiras oblíquas em relação à costa, inconspícuas. Soros dispostos ao longo das nervuras, geralmente superficiais ou às vezes ligeiramente imersos no tecido laminar; esporos triletes.

Material examinado: BRASIL. Pará: Moju, trilha Ducke ca. $02^{\circ} 11^{\prime} 0,19^{\prime \prime}$ S- $48^{\circ} 47^{\prime} 45,1^{\prime \prime} \mathrm{W}, 2 / \mathrm{VIII} / 2006$, S. Maciel et al. 100 (MG, MBM); Trilha Murça Pires ca. $02^{\circ} 11^{\prime} 0,13^{\prime \prime S}$ 48 47’45, '”, 4/VIII/2006, S. Maciel et al. 163 (MG); margem do rio Carioca ca. $02^{\circ} 08^{\prime} 47,7^{\prime \prime} \mathrm{S}-48^{\circ} 48^{\prime} 12,1$ 'W, 5/ XII/2006, S. Maciel \& M.R. Pietrobom 220 (MG); ramal da vila Santa Teresinha ca. $02^{\circ} 10^{\prime} 10,8^{\prime \prime}$ S- $48^{\circ} 42^{\prime} 41,2^{\prime \prime} \mathrm{W}, 6 /$ XII/2006, S. Maciel \& M.R. Pietrobom 269 (MG). 
Espécie com distribuição Americana. No Brasil é citada para o Acre, Amapá, Amazonas, Pará, Pernambuco e Roraima. $\mathrm{Na}$ área estudada cresce nas árvores próximas as trilhas em floresta de igapó, na margem dos rios e no interior da mata de terra firme.

Polytaenium guayanense caracteriza-se por apresentar no caule raízes densamente tomentosas com tricomas amarelados, formando aspecto esponjoso. O pecíolo abaxialmente é paleáceo, a costa é percorrente, proeminente na face abaxial e esverdeada na base. E ainda as aréolas formam fileiras oblíquas em relação à costa.

8. Vittaria Sm., Mém. Acad. Roy. Sci. (Turin) 5: 413, pl. 9. 1793.

Gênero com cinco espécies neotropicais e uma única espécie (V. isoetifolia Bory) ocorrendo na África e ilhas do
Oceano Índico (Mickel \& Smith 2004). Na flora do Estado do Pará é conhecida para o gênero apenas uma espécie.

Vittaria caracteriza-se pelas frondes estreitas, lineares, simples e inteiras, soros submarginais lineares e única fileira de aréolas entre a costa e a margem da lâmina (Mickel \& Smith 2004).

8.1. Vittaria lineata (L.) Sm., Mém. Acad. Roy. Sci. (Turin) 5: 421. t. 9. f. 5. 1793 .

Fig. 25-26

Plantas epífitas. Caule curto-reptante, com escamas castanhas, linear-lanceoladas, margem denticulada, ápice longamente filiforme, lustrosas, clatradas. Frondes 4,5-32 cm compr., até ca. 0,3 cm larg., fasciculadas, monomórficas; pecíolo ausente ou até $0,4 \mathrm{~cm}$ compr., paleáceo, achatado,

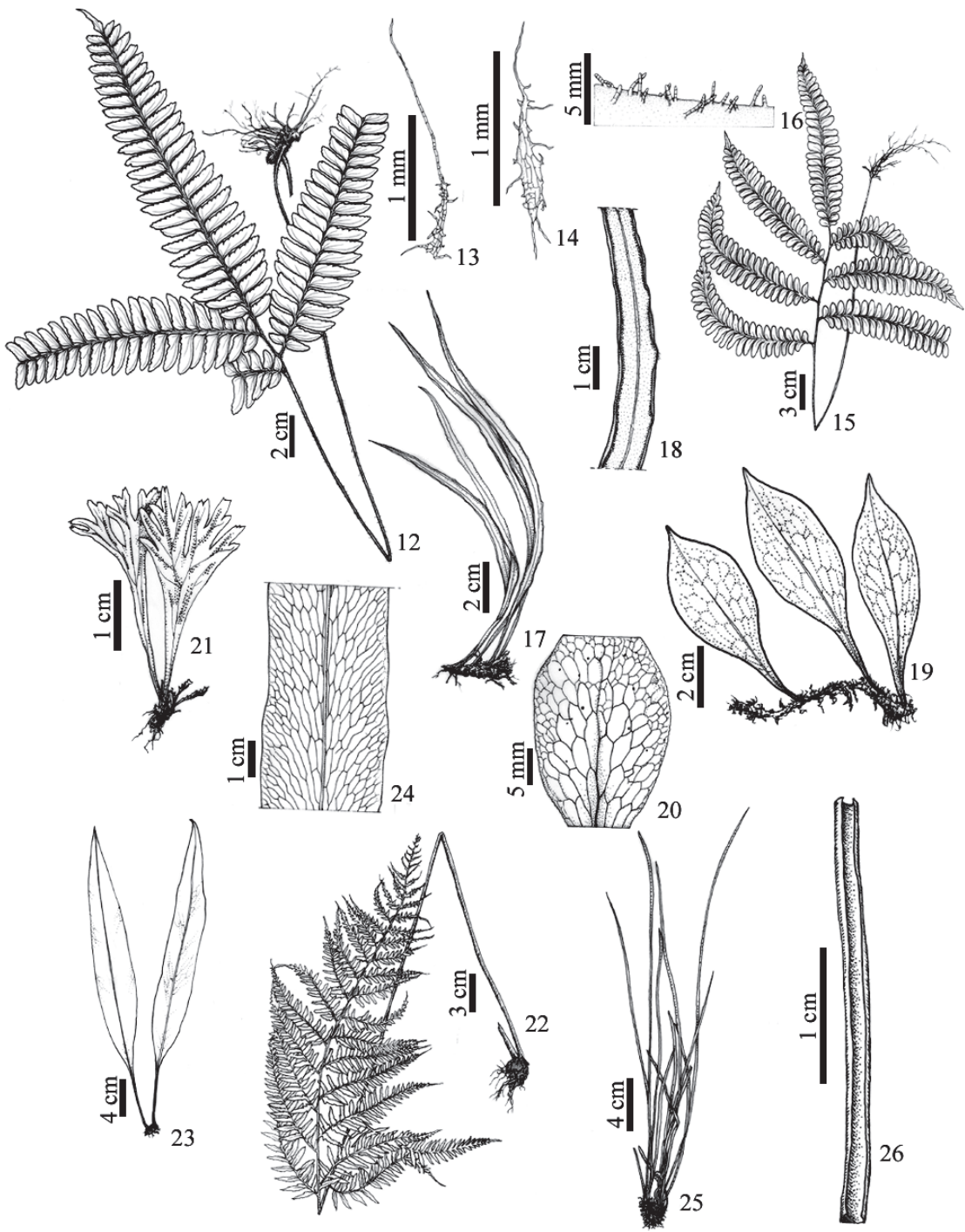

Figuras 12-26. Adiantum tetraphyllum Humb. \& Bonpl. ex Willd. 12. Hábito. 13-14. Escamas da raque (Maciel \& Pietrobom 299). Adiantum tomentosum Kunze. 15. Hábito. 16. Tricomas da raque (Maciel \& Pietrobom 229). Ananthacorus angustifolius (Sw.) Underw. \& Maxon. 17. Hábito. 18. Lâmina fértil (Maciel et al. 122). Anetium citrifolium (L.) Splitg. 19. Hábito. 20. Venação (Maciel \& Pietrobom 239). Hecistopteris pumila (Spreng.) J. Sm. 21. Hábito (Maciel et al. 127). Pityrogramma calomelanos (L.) Link var. calomelanos. 22. Hábito (Maciel et al. 157). Polytaenium guayanense (Hieron.) Alston. 23. Hábito. 24. Venação (Maciel et al. 100). Vittaria lineata (L.) Sm. 25. Hábito. 26. Lâmina revoluta (Maciel \& Pietrobom 286). 
estreitamente alado; lâmina cartácea, linear, glabra, margens revolutas; costa concolor, proeminente; venação anastomosada, com somente uma fileira de aréolas alongadas entre a costa e a margem, sem vênulas livres inclusas. Soros contínuos, marginais; paráfises filiformes, freqüentemente ramificadas, com célula apical não ou apenas levemente expandida; esporos monoletes.

Material examinado: BRASIL. Pará: Moju, trilha Murça Pires ca. $02^{\circ} 11^{\prime} 0,13^{\prime}$ 'S- $48^{\circ} 47^{\prime} 45,1^{\prime \prime} \mathrm{W}, 4 / \mathrm{VIII} / 2006, S$. Maciel et al. 173 (MG; MBM); margem do rio Carioca ca. $02^{\circ} 08^{\prime} 47,7^{\prime \prime} \mathrm{S}-48^{\circ} 48^{\prime} 12,1$ 'W, 5/XII/2006, S. Maciel \& M.R. Pietrobom 226 (MG); trilha bacurizal ca. 02 11 '54,2"S484'33,6”W, 7/XII/2006, S. Maciel \& M.R. Pietrobom 286 (MG).

Espécie com distribuição americana. No Brasil é citada para o AC, AL, AP, AM, BA, CE, ES, MA, MT, MS, MG, PA, PB, PR, PE, RJ, RS, RO, SC e SP. Na área estudada cresce em arvoretos no interior da mata de terra firme ou em floresta de igapó próximo às margens dos rios.

Vittaria lineata pode ser facilmente reconhecida, no Campo Experimental da Embrapa, principalmente pela fronde com cerca de $0,3 \mathrm{~cm}$ de largura com lâmina linear e margens revolutas. Os soros são contínuos e a venação apresenta somente uma fileira de aréolas alongadas entre a costa e a margem.

\section{Considerações finais}

No Campo Experimental da Embrapa Amazônia Oriental foram registradas 14 espécies, destas duas (Adiantum dolosum e A. multisorum) são novos registros para o estado do Pará. E a ocorrência de $A$. multisorum é de extrema importância para a preservação desta área, uma vez que esta espécie pode ser considerada rara para a Região Norte, sendo citada pela segunda vez para a referida região.

\section{Agradecimentos}

Os autores agradecem a Embrapa Amazônia Oriental por permitir a pesquisa na área de estudo; ao Dr. Jefferson Prado, do Instituto de Botânica de São Paulo, por confirmar e/ou identificar algumas espécies do gênero Adiantum; a Dr. ${ }^{a}$ Anna Luiza Ilkiu Borges, do Museu Paraense Emílio Goeldi, pela confecção do abstract; ao ilustrador botânico Carlos Avarez, do Museu Paraense Emílio Goeldi, pela confecção das ilustrações e ao Conselho Nacional de Desenvolvimento Científico e Tecnológico pela concessão de bolsa para o primeiro autor.

\section{Referências bibliográficas}

Barros, I.C.L.; Santiago, A.C.P.; Xavier, S.R.S.; Pietrobom, M.R. \& Luna, C.P L. 2002. Diversidade e aspectos ecológicos das pteridófitas (avencas, samambaias e plantas afins) ocorrentes em Pernambuco. Pp. 153-171. In: M. Tabarelli, \& J.M.C. Silva (Org.). Diagnóstico da biodiversidade de Pernambuco. v.1. Recife, Massangana e SECTMA.

Bastos, C.C.C. \& Cutrim, M.V.J. 1999. Pteridoflora da Reserva Florestal do Sacavém, São Luiz - Maranhão. Boletim do Museu Paraense Emílio Goeldi - Série Botânica 15(1): 3-37.

Boldrin, A.H.L. \& Prado, J. 2007. Pteridófitas Terrestres e Rupícolas do Forte dos Andradas, Guarujá, São Paulo, Brasil. Boletim de Botânica Universidade de São Paulo 25(1): 1-69.

Brade, A.C. 1940. Contribuição para o Estudo da Flora Pteridophyta da Serra de Baturité Estado do Ceará. Rodriguésia 4(13): 289-314.
Brade, A.C. 1947. Contribuição para o conhecimento da Flora do Estado do Espírito Santo (I. Pteridophyta). Rodriguésia 10(21): 25-33.

Brade, A.C. 1965a. Contribuição para o conhecimento das espécies brasileiras do gênero Doryopteris.J. Sm. (Polypodiaceae). Arquivo Jardim Botânico do Rio de Janeiro 18: 39-72.

Brade, A.C. 1965b. Filices Novae Brasilienses - X. Sellowia 17(17): 51-60. Braga, R. 1951. Pteridófitas Cearenses. Fortaleza, Editora Instituto do Ceará. Ching, R.C. 1940. On natural classification of the family "Polypodiaceae". Sunyatsenia 5: 201-268.

Copeland, E.B. 1947. Genera Filicum. Waltham, Chronica Botanica.

Crane, E.H. 1997. A Revised Circumscription of the Genera of the Fern Family Vittariaceae. Systematic Botany 22(3): 509-517.

Cremers, G. 1997. Group II. Pterophyta. Pp. 65-162. In S.A. Mori; G. Cremers, C. Gracie; J.-J. de Granville, M. Hoff \& J.D. Mitchell (eds.). Guide to the Vascular Plants of Central French Guiana. Part 1. Pteridophytes, Gymnosperms and Monocotyledons. New York, The New York Botanical Garden.

Felix, L.P.; Sousa, M.A. \& Oliveira, I.C. 1996. Pteridófitas do Herbário Prof. Jayme Coelho de Moraes (EAN), Areia - Paraíba, Brasil: I Vittariaceae. Revista Nordestina de Biologia 11(1): 57-71.

Fernandes, S.R.; Conceição, G.M.; Brito, E.S. \& Paula-Zárate, E.L. 2007. Diversidade Florística de Pteridófitas da Área de Preservação Ambiental do Inhamum, Caxias, Maranhão, Brasil. Revista Brasileira de Biociências 5(2): 411-413.

Fidalgo, O. \& Bononi, V.L.R. 1989. Técnicas de coleta, prevenção e herborização de material botânico. São Paulo, Instituto de Botânica.

Hyeronymus, G. 1909. Plantae Stübelianae. Pteridophyta. Hedwigia 48 : 215-503.

IBGE - Fundação Instituto Brasileiro de Geografia e Estatística. 1992. Manual Técnico da Vegetação Brasileira. Rio de Janeiro, IBGE.

Kelloff, C.L. \& Mckee, G.S. 1998. A New Species of Hecistopteris from Guyana, South America. American Fern Journal 88(4): 155-157.

Kramer, K.U. 1978. The pteridophytes of Suriname. Utrecht, Societas Investigatrix historiae Naturalis Suriname et Antillarum Neerlandicarum.

Krieger, L. \& Camargo, R.F.N. 1985. Pteridófitos da Zona da mata de Minas Gerais encontrados no Herbário da Universidade Federal de Juiz de

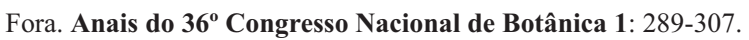

Labiak, P.H. \& Prado, J. 1998. Pteridófitas epífitas da reserva Volta Velha, Itapoá - Santa Catarina, Brasil. Boletim de Botânica Universidade de São Paulo 11: 1-79.

Lellinger, D.B. 1991. Common and confusing bipinnate-dimidiate Adiantums of Tropical America. American Fern Journal 81: 99-102.

Lellinger, D.B. 2002. A Modern Multilingual Glossary for Taxonomic Pteridology. Pteridologia 3A. Washington, American Fern Society.

Lellinger, D. B. \& Prado, J. 2001. The group of Adiantum gracile in Brazil and environs. American Fern Journal 91(1): 1-8.

Maciel, S.; Souza, M.G.C.; \& Pietrobom, M.R. 2007. Licófitas e monilófitas o Bosque Rodrigues Alves Jardim Botânico da Amazônia, município de Belém, estado do Pará, Brasil. Boletim do Museu Paraense Emílio Goeldi. Ciências Naturais 2(2): 69-83.

Melo, L.C.N. \& Salino, A. 2002. Pteridófitas de duas áreas de floresta da Bacia do Rio Doce no Estado de Minas Gerais, Brasil. Lundiana 3(2): 129-139.

Mickel, J.T. \& Smith, A.R. 2004. The Pteridophytes of Mexico. Memoirs of The New York Botanical Garden 88: 1-1055.

Moran, R.C. 1995a. Acrostichum. Pp. 105-106. In: R.C, Moran \& R. RIBA (eds.). Psilotaceae a Salviniaceae. In: G. Davidse; M. Sousa \& S. Knapp (eds.). Flora Mesoamericana. v.1. México, Universidad Nacional Autónoma de México.

Moran, R.C. 1995b. Vittariaceae. Pp. 145-150. In: R.C, Moran \& R. RIBA (eds.). Psilotaceae a Salviniaceae. In: G. Davidse; M. Sousa \& S. Knapp (eds.). Flora Mesoamericana. v.1. México, Universidad Nacional Autónoma de México.

Moran, R.C. 1995c. Pityrogramma. Pp. 137-140. In: R.C, Moran \& R. RIBA (eds.). Psilotaceae a Salviniaceae. In: G. Davidse; M. Sousa \& S. Knapp (eds.). Flora Mesoamericana. v.1. México, Universidad Nacional Autónoma de México.

Moran, R.C. \& Yatskievych, G. 1995. Pteridaceae. Pp. 104-145. In: R.C, Moran \& R. Riba (eds.). Psilotaceae a Salviniaceae. In: G. Davidse; M. Sousa \& S. Knapp (eds.). Flora Mesoamericana. v.1. México, 
Universidad Nacional Autónoma de México.

Moran, R.C. \& Smith, A.R. 2001. Phytogeographic relationships between neotropical and African-Madagascar pteridophytes. Brittonia 53 : 304-351.

Moran, R.C. \& Yatskievych, G. 1995. Pteridaceae. Pp. 104-105. In: R.C, Moran \& R. RIBA (eds.). Psilotaceae a Salviniaceae. In: G. Davidse; M. Sousa \& S. Knapp (eds.). Flora Mesoamericana. v.1. México, Universidad Nacional Autónoma de México.

Moran, R.C.; Zimmer, B. \& Jermy, A.C. 1995. Adiantum. Pp. 106-108. In: R.C, Moran \& R. RIBA (eds.). Psilotaceae a Salviniaceae. In: G. Davidse; M. Sousa \& S. Knapp (eds.). Flora Mesoamericana. v.1, Ciudad de México: Universidad Nacional Autónoma de México.

Mori, S.A.; Boom, B.M.; Carvalho, A.M. \& Santos, T.S. 1983. Southern bahian moist forests. The Botanical Review 49(2): 155-232.

Nauman, C.E. 1985. New Pteridophyte Record for the Territory of Amapá, Brasil. Acta Amazonica 15(3-4): 303-305.

Nonato, F.R. \& Windisch, P.G. 2004. Vittariaceae (Pteridophyta) do Sudeste do Brasil. Revista Brasileira de Botânica 27(1): 149-161.

Oliveira, E.C.P.; Lameira, O.A. E. \& Zoghbi, M.G.B. 2006. Identificação da época de coleta do óleo-resina de copaíba (Copaifera spp.) no município de Moju, PA. Revista Brasileira de Plantas Medicinais 8(3): 14-23.

Paciencia, M.B. \& Prado, J. 2004. Efeitos de borda sobre a comunidade de pteridófitas na Mata Atlântica da região de Una, sul da Bahia, Brasil. Revista Brasileira de Botânica 27(4): 641-653.

Parris, B.S. 2001. Circum-Antarctic continental distribution patterns in pteridophyte species. Brittonia 53: 270-283.

Peixoto, M.F. 1984. Pteridophyta do Estado do Rio de Janeiro - Pequeno Comentário. Atas da Sociedade Botânica do Brasil: secção do Rio de Janeiro 2(19): 149-156.

Pichi-Sermolli, R.E.G. 1996. Authors of Scientifc names in Pteridophyta. Kew: Royal Botanical Garden.

Pietrobom, M.R. \& Barros, I.C.L. 2002. Pteridófitas de um remanescente de Floresta Atlântica em São Vicente Férrer, Pernambuco, Brasil: Pteridaceae. Acta Botanica Brasilica 16(4): 73-118.

Pietrobom, M.R. \& Barros, I.C.L. 2006. Associações entre as espécies de pteridófitas em dois fragmentos de Floresta Atlântica do Nordeste Brasileiro. Biotemas 19(3): 15-26.

Prado, J. 1992. Flora da serra do Cipó, Minas Gerais: PteridaceaeCheilanthoideae. Boletim Botânico da Universidade de São Paulo 13: $141-159$.

Prado, J. 1993. A new species of Doryopteris (section Doryopteris Pteridaceae) from Brazil. Kew Bulletin 48(1): 13-16.

Prado, J. 1997. Flora da Serra do cipó, Minas Gerais: Pteridaceae Adiantoideae e Taenitidoideae. Boletim Botânico da Universidade de São Paulo 16: 115-118.

Prado, J. 2000. A new species of Adiantum (Pteridaceae) from Bahia, Brazil. Brittonia 52(2): 210-212.

Prado, J. 2001. Adiantum giganteum (Pteridaceae: Pteridophyta) a new maidenhair fern from amazonia, Brazil. Fern Gazette 16(5): 209-212.

Prado, J. 2003. New Species in Adiantum from Brazil. American Fern Journal 93(2): 76-80.

Prado, J. 2004. Criptógamos do Parque Estadual das Fontes do Ipiranga, São Paulo, SP. Pteridophyta: 17. Pteridaceae. Hoehnea 31(1): 39-49.

Prado, J. 2005a. Flora da Reserva Ducke, Amazonas, Brasil: Pteridophyta - Pteridaceae. Rodriguésia 56(86): 85-92.

Prado, J. 2005b. Pteridaceae da Reserva Ecológica de Macaé de Cima, Nova Friburgo, Rio de Janeiro, Brasil. Rodriguésia 56(87): 179-184.

Prado, J. 2005c. Pteridaceae. Pp. 183-216. In: T.B. Cavalcanti \& A.E. Ramos (Orgs.). Flora do Distrito Federal, Brasil. v. 4, Brasília, Embrapa Recursos Genéticos e Biotecnologia.
Prado, J. \& Windisch, P.G. 2000. The genus Pteris L. (Pteridaceae) in Brazil. Boletim do Instituto de Botânica 13: 103-199.

Prado, J.; Rodrigues, C.D.N.; Salatino, A. \& Salatino, M.L.F. 2007. Phylogenetic relationships among Pteridaceae, including Brazilian species, inferred from rbcL sequences. Taxon 56(2): 355-368.

Rodrigues-Jr., C.E. 2000. Vittariaceae (C. Presl) Ching from the state park of Campos do Jordão-SP, Brazil. Boletim do Herbário Ezechias Paulo Heringer 5: 95-104.

Rodrigues, S.T.; Almeida, S.S. de; Andrade, L.H.C.; Barros, I.C.L. \& van den Berg, M.E. 2004. Composição florística e abundância de pteridófitas em três ambientes da bacia do rio Guamá, Belém, Pará, Brasil. Acta Amazonica 34(1): 35-42.

Sampaio, A.J. 1916. Pteridophytas. Pp. 4-34. In: F.C. Hoehne (ed.). Comissão das Linhas Telegráficas Estratégicas Mato-Grosso ao Amazonas, 33.

Sampaio, A.J. 1930. Eufilicíneas do Rio Cuminá. Arquivos do Museu Nacional 32: 8-60.

Schwartsburd, P.B. \& Labiak, P.H. 2007. Pteridófitas do Parque Estadual de Vila Velha, Ponta Grossa, Paraná, Brasil. Hoehnea 34(2): 159-209.

Sehnem, A. 1959. Uma coleção de pteridófitos do Rio Grande do Sul, III. Pesquisas 3: 495-576.

Sehnem, A. 1972. Pteridáceas. Pp. 1-244. In: R. Reitz (ed.). Flora Ilustrada Catarinense. Itajaí: Herbário Barbosa Rodrigues.

Serrão, D.R.; Jardim, F.C.S \& Nemer, T.C. 2003. Sobrevivência de seis espécies florestais em uma área explorada seletivamente no município de Moju, Pará. Cerne 9(2): 153-163.

Smith, A.R. 1990. Pteridophytes of the Venezuelan Guayana: New Species. Annals of the Missouri Botanical Garden 77(2): 249-273.

Smith, A.R. \& Lellinger, D.B. 1995. Pteridaceae. Pp. 250-286. In: P.E. Berry; B.K. Holst \& K. Yatskievych (eds.). Pteridophytes, Spermatophytes: Acanthaceae-Araceae. In: J.S. Steyermark; P.E. Berry \& B.K. Holst (eds.). Flora of the Venezuelan Guayana. v.2, Portland, Timber Press.

Smith, A.R.; Pryer, K.M.; Schuettpelz, E.; Korall, P.; Schneider, H. \& Wolf, P.G. 2006. A classification for extant ferns. Taxon 55(3): 705-731.

Tryon, R.M. 1962. The fern genus Doryopteris in Santa Catarina and Rio Grande do Sul, Brazil. Sellowia 14: 51-59.

Tryon, R.M. \& Conant, A.S. 1975. The ferns of Brazilian Amazonica. Acta Amazonica 5: 23-34Tryon, R.M. \& Stolze, R.G. 1989. Pteridophyta of Peru. Part. II. 13. Pteridaceae - 15. Dennstaedtiaceae. Fieldiana Botany 22: 1-128.

Tryon, R.M. \& Tryon, A.F. 1982. Ferns and Allied Plants, with Special Reference to Tropical America. New York, Springer Verlag.

Tryon, R.M., Tryon, A.F. \& Kramer, K.U. 1990. Pteridaceae. Pp. 230256. In: K. U. Kramer \& P.S. Green (vol. eds.), Pteridophytes and Gymnosperms. In: K. Kubitzki, (ed.). The Families and Genera of Vascular Plants. v. 1. Berlin, Springer Verlag.

Windisch, P.G. 1979. Adições ao inventário das pteridófitas do Acre. Bradea 3(5): 29-30.

Windisch, P.G. 1992. Pteridófitas da Região Norte-Ocidental do Estado de São Paulo - Guia para excursões. 2.ed. São José do Rio Preto, UNESP.

Windisch, P.G. \& Nonato, F.R. 1999. Pteridófitas do estado do Mato Grosso, Brasil: Vittariaceae. Acta Botanica Brasilica 13(3): 290-297.

Windisch, P.G. \& Tryon, R.M. 2001. The Serra Ricardo Franco (State of Mato Grosso, Brazil) as probable migration route and its present fern flora. Bradea 8(39): 267-276.

Winter, S.L.S.; Mynssen, C.M. \& Prado, J. 2007. Adiantum (Pteridaceae) no Arboreto do Jardim Botânico do Rio de Janeiro, Brasil. Rodriguésia 58(4): $847-858$ 